\title{
Wet regeneration of waste artificial sand used in sand casting using chemical solutions
}

\author{
Eun Yeong Ko ${ }^{1,2}$, Kyeong Ho Kim¹, Jae Ho Baek ${ }^{1}$, Inseong Hwang ${ }^{2}$, Man Sig Lee ${ }^{1,3^{\dagger}}$ \\ ${ }^{1}$ Ulsan Division, Korea Institute of Industrial Technology (KITECH), Korea \\ ${ }^{2}$ Department of Civil and Environmental Engineering, Pusan National University, Korea \\ ${ }^{3}$ Green Process \& System Engineering Department, University of Science \& Technology (UST), Korea
}

\begin{abstract}
Natural sand and organic binders have been the main materials used in sand casting. However, inorganic binders are used in novel casting technologies, and research on artificial sand as a substitute of natural sand has been conducted. Herein, the wet regeneration of waste artificial sand was performed using a sodium silicate binder. Acidic, neutral, and basic solutions were used for wet regeneration. The effects of binder removal and reusability of the regenerated sand were investigated by comparing the characteristics and strengths of the artificial and regenerated sand. It was demonstrated that the basic solution effectively removed the binder from the surface of the waste artificial sand. The Si-O-Si bond cleavage in the binder occurred due to the high concentration of hydroxide ions in the basic solution. The strength of the regenerated sand treated with the basic solution and that of the artificial sand were similar. Moreover, the strengths of regenerated sands treated with the acidic or neutral solutions were lower than that of artificial sand due to the presence of residual binder. These results indicated that the basic solution was suitable for removing the sodium silicate binder. The quality of the regenerated sand was similar to that of artificial sand.
\end{abstract}

Keywords: Artificial sand, Sodium silicate binder, Waste foundry sand, Wet regeneration

\section{Introduction}

Natural sand is mainly used for making molds in sand casting, and waste foundry sand (WFS) from the casting process is discarded on landfills $[1,2]$ or reused as concrete and ceramic materials [3-7]. WFS disposal on landfills may cause not only an increase in operational costs but also environmental pollution. WFS contains toxic heavy metals and particulate matters that can leach into the ground and result in soil and ground water pollution [1, 2]. Moreover, this leads to additional disposal costs due to the need for remediation and complying regulations. In addition, landfill sites are becoming insufficient due to increasing WFS volumes, so they are not currently an effective disposal method. The foundry industry must comply with environmental protection and resource conservation regulations [8]. Therefore, it is necessary to develop an appropriate regeneration method to reuse WFS in the casting process.

Several studies have been conducted using artificial sand to overcome the limitations of natural sand [9-11]. The use of artificial sand for making molds is advantageous for several reasons. First, high-durability artificial sand cannot be easily crushed and produces less dust [9]. Second, spherical artificial sand requires less amounts of binder for an specific mold volume, which decreases the amount of gas generated during casting and results in better casting quality [10]. Despite these advantages, the high cost of artificial sand mainly limits its applications [11]. Therefore, efficient regeneration methods should be developed to compensate that limitation and to reduce its disposal cost after casting.

Typically, there are three different methods to regenerate WFS: dry, thermal, and wet regeneration [12]. Dry regeneration removes the binder on the sand surface using friction, making this process significantly simple compared to other methods. However, the co-produced dust during dry regeneration negatively affects the working environment and the quality of the regenerated sand [12, 13]. Thermal regeneration removes the binder using a high-temperature treatment $\left(>600^{\circ} \mathrm{C}\right)$, which is energy costly and causes the emission of harmful gases [13]. In contrast, wet regeneration uses water and chemical solutions for binder removal, and produces
This is an Open Access article distributed under the terms of the Creative Commons Attribution Non-Commercial License (http://creativecommons.org/licenses/by-nc/3.0/) which permits unrestricted non-commercial use, distribution, and reproduction in any medium, provided the original work is properly cited.

Copyright (C) 2021 Korean Society of Environmental Engineers
Received July 28, 2020 Accepted October 30, 2020

${ }^{\dagger}$ Corresponding author

Email: lms5440@kitech.re.kr

Tel: +82-52-980-6630 Fax: +82-52-980-6639

ORCID: 0000-0003-1565-9222 
better-quality reused sand than other methods [12, 14].

The waste sand used herein was prepared from water glass binder on artificial sand, and it was recycled through wet regeneration. The purpose of this study was to determine the effect of the chemical solutions on binder removal and to evaluate the reusability of the regenerated sand. Typically, representative acidic and basic solutions are used for regeneration. The use of oxalic acid [15] and hydrochloric acid [16] as the acidic solutions has been reported, while sodium hydroxide [17] and potassium hydroxide have been used as basic solutions. Because the silica component on the sand surface cannot be removed with acid solutions [18], most studies used basic solutions. Herein, potassium hydroxide, being one constituent of the binder, was chosen among the base solutions for the experiments. Hydrochloric acid was used as the acidic solution based on our prior research [19], and deionized water was utilized as a $\mathrm{pH}$ reference material. The effect of the solution type on binder removal was confirmed by comparing the resulting characteristics in the regenerated sand, based on chemical composition, surface and particle size analysis, and flexural strength.

\section{Experimental}

\subsection{Preparation of the Waste Artificial Sand}

The artificial sand (Simat International Limited Company, Hong Kong) and 2 wt\% of sodium silicate-based binder [20] were mixed at $220 \mathrm{rpm}$ for $120 \mathrm{~s}$ (device from Youngin Machinery Co., Ltd, Korea). The mixed sand was formed into a core (device from Youngjin Machinery Co., Ltd, Korea) at a pressure of 4 bar. Hot air $\left(150^{\circ} \mathrm{C}\right)$ was blown into the core for $30 \mathrm{~s}$ to harden the binder. The produced $22.4 \times 22.4 \times 170 \mathrm{~mm}(\mathrm{~W} \times \mathrm{L} \times \mathrm{H})$ core was used as the waste artificial sand. The chemical compositions of laboratory-made and waste site-generated artificial sand were almost equivalent based on previous reports, making valid to carry out the experiments using laboratory-made artificial sand.

\subsection{Regeneration process}

Three different chemical solutions (based on hydrochloric acid, deionized water, and potassium hydroxide) were used separately to act as the chemical solution (Fig. 1) for wet regeneration of the waste artificial sand, and the effects of these solutions were compared. The concentrations of the acidic and basic solutions were $0.2 \mathrm{M}$ hydrochloric acid ( $\mathrm{HCl}$; purity: $35 \%$, grade: EP, Daejung Chemical \& Metals Co., Ltd, Korea) and 0.2 M potassium hydroxide (KOH; purity 85\%, grade: EP, Daejung Chemical \& Metals Co., Ltd, Korea), respectively. Deionized (DI) water was used as the neutral solution for wet regeneration.

Fig. 1 shows the schematic of the regeneration process. 500 $\mathrm{g}$ of waste artificial sand and $500 \mathrm{~mL}$ of chemical solution were stirred at $250 \mathrm{rpm}$ for $20 \mathrm{~min}$ (HT-120DX, Daihan, Korea), and the reactor temperature was maintained at $60^{\circ} \mathrm{C}$ using a water bath (BW-20G, Jeio Tech, Korea). After stirring, the sand was separated from the mixture using an aspirator (WEV-00.S, Daihan, Korea) and a metal mesh (no. 300; sieve mesh $46 \mu \mathrm{m}$ ). Because the $\mathrm{pH}$ value of the separated sand was altered by the chemical solution,

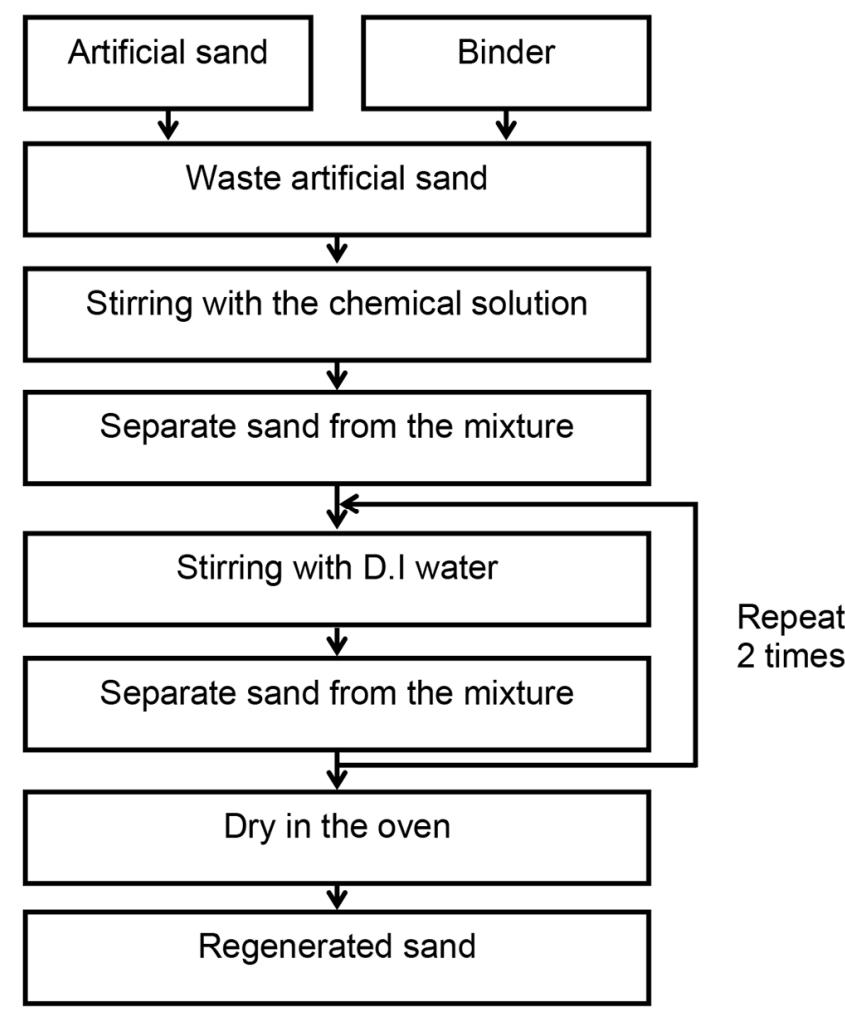

Fig. 1. Flowchart of the regeneration process.

the same process was repeated three times using DI water for neutralizing the $\mathrm{pH}$ of the sand. The regenerated sand was dried at $105^{\circ} \mathrm{C}$ for $2 \mathrm{~h}$ using an oven.

The three regenerated sand samples were denoted according to the regeneration media used as sand treated with the basic solution (B1), sand treated with the neutral solution (N1), and sand treated with the acid solution (A1), respectively. N1 and A1 were re-treated with the $\mathrm{KOH}$ solution according to the regeneration process and subsequently labelled as N2 and A2.

\subsection{Analysis Methods}

X-ray fluorescence spectroscopy (XRF, Zetium, PANalytical, Netherlands) was used to compare the elemental compositions of the regenerated sand and artificial sand. Zeta potential measurements (ZetaPALS, Brookhaven, USA) were used to confirm the surface charge on the sand. $0.5 \mathrm{~g}$ of each sand sample was dispersed in $1 \mathrm{~mL}$ of $\mathrm{DI}$ water. The data for all samples were analyzed from five replicates.

Field emission scanning electron microscopy (FE-SEM, SU 8020, Hitachi, Japan) and energy dispersive X-ray spectroscopy (EDS, X-Max50 011, Horiba, Japan) were used for surface analysis of the sand samples.

Particle size distributions were obtained by mechanical sieving as follows: dried sand (100 g) was passed through a series of sieves stacked up in increasing mesh order $(850,600,425,300,212$, $150,105,75,53$, and $0 \mu \mathrm{m})$. The sieves were shaken for $3 \mathrm{~min}$ using a sieve shaker (CG-211-8, Chunggye, Korea), and the sample weights in each sieve were recorded. The particle distributions 
Table 1. Chemical Compositions of Artificial Sand, Waste Artificial Sand, and Regenerated Sand

\begin{tabular}{|c|c|c|c|c|c|c|c|}
\hline \multirow{2}{*}{ Element } & \multirow{2}{*}{$\begin{array}{l}\text { Artificial sand } \\
\text { (wt\%) }\end{array}$} & \multirow{2}{*}{$\begin{array}{l}\text { Waste artificial sand } \\
\text { (wt\%) }\end{array}$} & \multicolumn{3}{|c|}{ Regenerated sand (wt\%) } & \multicolumn{2}{|c|}{ Re-treated sand (wt\%) } \\
\hline & & & B1 & N1 & A1 & N2 & A2 \\
\hline $\mathrm{Na}_{2} \mathrm{O}$ & 0.08 & 1.90 & 0.07 & 0.06 & 0.06 & 0.06 & 0.06 \\
\hline $\mathrm{Al}_{2} \mathrm{O}_{3}$ & 67.50 & 60.48 & 67.44 & 66.31 & 65.84 & 68.54 & 69.10 \\
\hline $\mathrm{SiO}_{2}$ & 18.02 & 23.54 & 17.96 & 20.01 & 21.27 & 18.11 & 17.65 \\
\hline $\mathrm{K}_{2} \mathrm{O}$ & 1.85 & 2.08 & 1.85 & 1.87 & 1.76 & 1.87 & 1.81 \\
\hline $\mathrm{TiO}_{2}$ & 5.32 & 5.08 & 5.40 & 5.14 & 5.02 & 5.08 & 5.08 \\
\hline $\mathrm{Fe}_{2} \mathrm{O}_{3}$ & 5.11 & 4.63 & 5.13 & 4.55 & 4.19 & 4.41 & 4.46 \\
\hline others & 2.12 & 2.29 & 2.15 & 2.06 & 1.86 & 1.93 & 1.84 \\
\hline
\end{tabular}

and the corresponding America Foundry Society (AFS) grain fineness numbers were calculated using the sieve data. All variables were obtained from triplicate data.

The strength was tested using a core (prepared as the same as the waste artificial sand) as the specimen. The specimens were stored under different conditions. Under normal conditions, they were stored at a temperature of $20^{\circ} \mathrm{C}$ and relative humidity $(\mathrm{RH})$ of $30 \%$ for $1 \mathrm{~min}$ and $60 \mathrm{~min}$. Under humid conditions, they were stored at a temperature of $38{ }^{\circ} \mathrm{C}$ and $\mathrm{RH}$ of $65 \%$ for $120 \mathrm{~min}$. The specimens for analysis under the humidity condition were stored for 60 min under normal condition and then taken to the humidity condition. The strengths of the specimens were evaluated after storage. The temperature and humidity were maintained using a chamber (TH-DG-150, JEIO Tech, Korea). The strength of the regenerated sand was measured after adding $2 \%$ of the binder to the regenerated sand. For each sample, the strength was measured from triplicate data.

Differential scanning calorimetry (DSC, DSC 3, Mettler Toledo, Switzerland) curves were constructed under nitrogen at a heating rate of $20^{\circ} \mathrm{C} / \mathrm{min}$ and at temperatures in the range of $30-400^{\circ} \mathrm{C}$.

\section{Results and Discussion}

\subsection{Elemental Sand Composition}

Table 1 shows the chemical composition of the artificial sand, waste artificial sand, and regenerated sand, which were determined by XRF analysis. All samples were composed primarily of $\mathrm{Na}_{2} \mathrm{O}$, $\mathrm{Al}_{2} \mathrm{O}_{3}, \mathrm{SiO}_{2}, \mathrm{~K}_{2} \mathrm{O}, \mathrm{TiO}_{2}$, and $\mathrm{Fe}_{2} \mathrm{O}_{3}$. As shown in Table 1, the $\mathrm{Na}_{2} \mathrm{O}$ and $\mathrm{SiO}_{2}$ contents for the waste artificial sand were higher than that for the artificial sand, because a sodium silicate-based binder was used.

The sodium silicate binder bridged the sand particles by dehydration and condensation reactions, as shown in Eq. (1) and (2) [21, 22].

$$
\begin{gathered}
\text { Dehydration } \equiv \mathrm{Si}-\mathrm{ONa}^{+}+\mathrm{H}_{2} \mathrm{O} \rightarrow \\
\equiv \mathrm{Si}-\mathrm{OH}+\mathrm{Na}^{+}+\mathrm{OH} \\
\text { Condensation } \equiv \mathrm{Si}-\mathrm{OH}+\mathrm{OH}-\mathrm{Si} \equiv \rightarrow \\
\equiv \mathrm{Si}-\mathrm{O}-\mathrm{Si}+\mathrm{H}_{2} \mathrm{O}
\end{gathered}
$$

The bridges were mainly formed by the Si-O-Si bonds, whereas sodium was not bonded to the structure or present on the silica or sand surface in its ionic state [21, 23]. Because sodium ions do not participate in binder bridges formation, the sodium content in the samples was easily removed through the regeneration process [24]. The $\mathrm{Na}_{2} \mathrm{O}$ contents for B1, N1 and $\mathbf{A 1}$ were $0.07 \%, 0.06 \%$, and $0.06 \%$, respectively. The $\mathrm{Na}_{2} \mathrm{O}$ contents for all the regenerated sand samples were lower than that of the waste artificial sand $(1.90 \%)$ and similar to that of the artificial sand (0.08\%). In addition, $\mathrm{SiO}_{2}$ contents for B1, N1 and A1 were 17.96\%, 20.01\%, and $21.27 \%$, respectively. The $\mathrm{SiO}_{2}$ content (which was the binder's main component) was used to determine whether the binder was removed or not. Considering the $\mathrm{SiO}_{2}$ content of the artificial sand as $18.02 \%$, it was confirmed that most binders were removed for B1. However, $\mathbf{N 1}$ and A1, having higher $\mathrm{SiO}_{2}$ content than that of the artificial sand, were considered to have remaining binders.

These results can be explained through the binder solubility dependence on the $\mathrm{pH}$ of the chemical solution. For the basic solution, Si-O-Si bonds cleavage in the binder occurred by chemical reaction with hydroxyl groups present in the basic solution (Eq. (3)) [25]. When using the acidic solution, silica was formed as $\mathrm{SiO}_{2}$ through the reaction with the acid, and then remained on the surface of the sand particles (Eq. (4)) [26].

$$
\begin{gathered}
\equiv \mathrm{Si}-\mathrm{O}-\mathrm{Si}+\mathrm{OH} \rightarrow \equiv \mathrm{Si}-\mathrm{OH}+\mathrm{Si}-\mathrm{O}^{-} \\
\mathrm{Na}_{2} \mathrm{SiO}_{3}+2 \mathrm{HCl} \rightarrow 2 \mathrm{NaCl}+\mathrm{H}_{2} \mathrm{O}+\mathrm{SiO}_{2}
\end{gathered}
$$

The zeta potential values of B1, N1 and A1 were $-29.45,-56.55$, and $-64.20 \mathrm{mV}$, respectively. The zeta potential value of the artificial sand was $-24.37 \mathrm{mV}$, similar to that of $\mathbf{B 1}$ regenerated with the alkali solution. N1 and A1 showed high zeta potential values due to the effect of residual binders. In particular, the zeta potential of $\mathbf{A 1}$ was the most negative due to negatively charged $\mathrm{SiO}_{2}$ that remained on the surface of the sand [27].

\subsection{Surface Analysis of Sand Particles}

Fig. 2 shows the scanning electron microscopy (SEM) images of the artificial sand, waste artificial sand, and regenerated sand. The artificial sand particles (Fig. 2(a)) were spherical and exhibited smooth surfaces. As shown in Fig. 2(c), a smooth surface with 

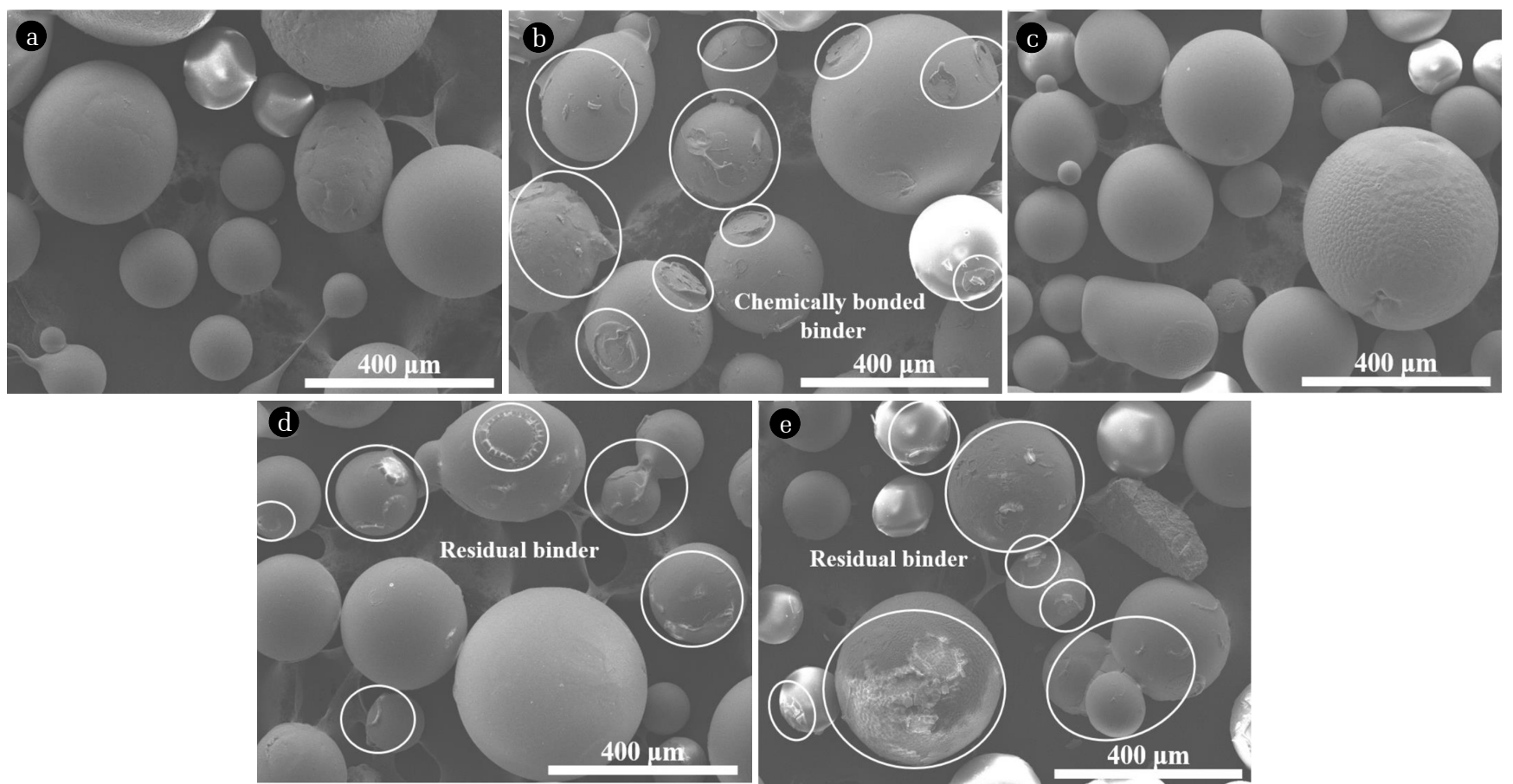

Fig. 2. SEM images of samples: (a) artificial sand, (b) waste artificial sand, (c) B1, (d) N1, and (e) A1.

no impurities were observed for $\mathbf{B} \mathbf{1}$ and its morphology was similar to that of the artificial sand. In addition, the surface of N1 was partially covered with impurities (Fig. 2(d)), while most of the surface of A1 had several impurities (Fig. 2(e)). The surface impurities for $\mathbf{N 1}$ and $\mathbf{A} 1$ were similar to that of the waste artificial sand (Fig. 2(b)).

Fig. 3 shows the EDS results for the artificial sand and regenerated sand. The EDS was conducted to detect $\mathrm{Al}, \mathrm{Si}$, and $\mathrm{Na}$ compounds, because these are the main components of the sand and the binder. The EDS mapping images in Figs. 3(a) and (b) showed that $\mathrm{Al}$ and $\mathrm{Si}$ compounds were uniformly distributed on both the surfaces of the artificial sand particles and B1. Moreover, their elemental contents were similar. As shown in Figs. 3(c) and (d), the Si composition was densely concentrated on the impurities of the sand surface for N1 and A1. Hence, the impurities were the products of the residual binder, which was not removed by the neutral and acidic solutions. The spectra in Fig. 3 revealed that the Si component gradually decreased in the following order: B1, N1 and A1.

\subsection{AFS and Particle Size Distributions}

Typically, sand strength is affected by the particle size, size distribution, shape, and storage humidity as well as the amount of binder and the $\mathrm{pH}$ value on the sand surface [28-30]. Fig. 4 shows the particle size distributions of the artificial sand and the regenerated sand. All samples had narrow particle size distributions, in the 150-425 $\mu \mathrm{m}$ mesh range. The calculated AFS values for the artificial sand sample, B1, N1 and A1 were 46, 45, 45, and 44 , respectively. It was assumed that this slight difference did not affect the strength directly.

\subsection{Flexural Strength}

The low core flexural strengths cannot be managed by operators and may be damaged during assembly, storage, and transport, and also may collapse the mold during casting [20]. Accordingly, the strength of the regenerated sand was tested to determine if it could be used as a substitute of artificial sand.

Fig. 5 shows the core strengths under different conditions. The flexural strengths of the artificial sand for 1 and 60 min were 218 and $325 \mathrm{~N} / \mathrm{cm}^{2}$, respectively. The initial strength for $1 \mathrm{~min}$ was high $\left(218 \mathrm{~N} / \mathrm{cm}^{2}\right)$, which indicated that it could be easily managed by an operator without causing any damage. The core was exposed to the normal condition at $150{ }^{\circ} \mathrm{C}$, and the binder was sufficiently hardened. The flexural strength after $60 \mathrm{~min}$ was higher than that obtained after $1 \mathrm{~min}$. The flexural strengths of B1 after 1 and 60 min were 220 and $320 \mathrm{~N} / \mathrm{cm}^{2}$, respectively. The strength of $\mathbf{B 1}$ was quite similar to that of the artificial sand. However, the flexural strengths of N1 and A1 after 60 min were 198 and $121 \mathrm{~N} / \mathrm{cm}^{2}$, respectively. The strength of $\mathbf{N 1}$ and A1 was considerably lower than that of the artificial sand and B1. This can be explained because $\mathbf{N 1}$ and $\mathbf{A 1}$ had a large amount of residual binder, which hindered the combination of regenerated sand and new binder. When the core was set to the humidity condition, its strength gradually decreased. The flexural strength of the artificial sand after $60 \mathrm{~min}$ under the normal condition was $325 \mathrm{~N} / \mathrm{cm}^{2}$; however, the flexural strength of the artificial sand after 120 min under the humidity condition was $220 \mathrm{~N} / \mathrm{cm}^{2}$. The flexural strengths of B1, N1 and A1 after $120 \mathrm{~min}$ were 194, 168, and $105 \mathrm{~N} / \mathrm{cm}^{2}$, respectively.

The core strength increased with increasing amounts of binder. However, because the characteristics of the residual binder in the 

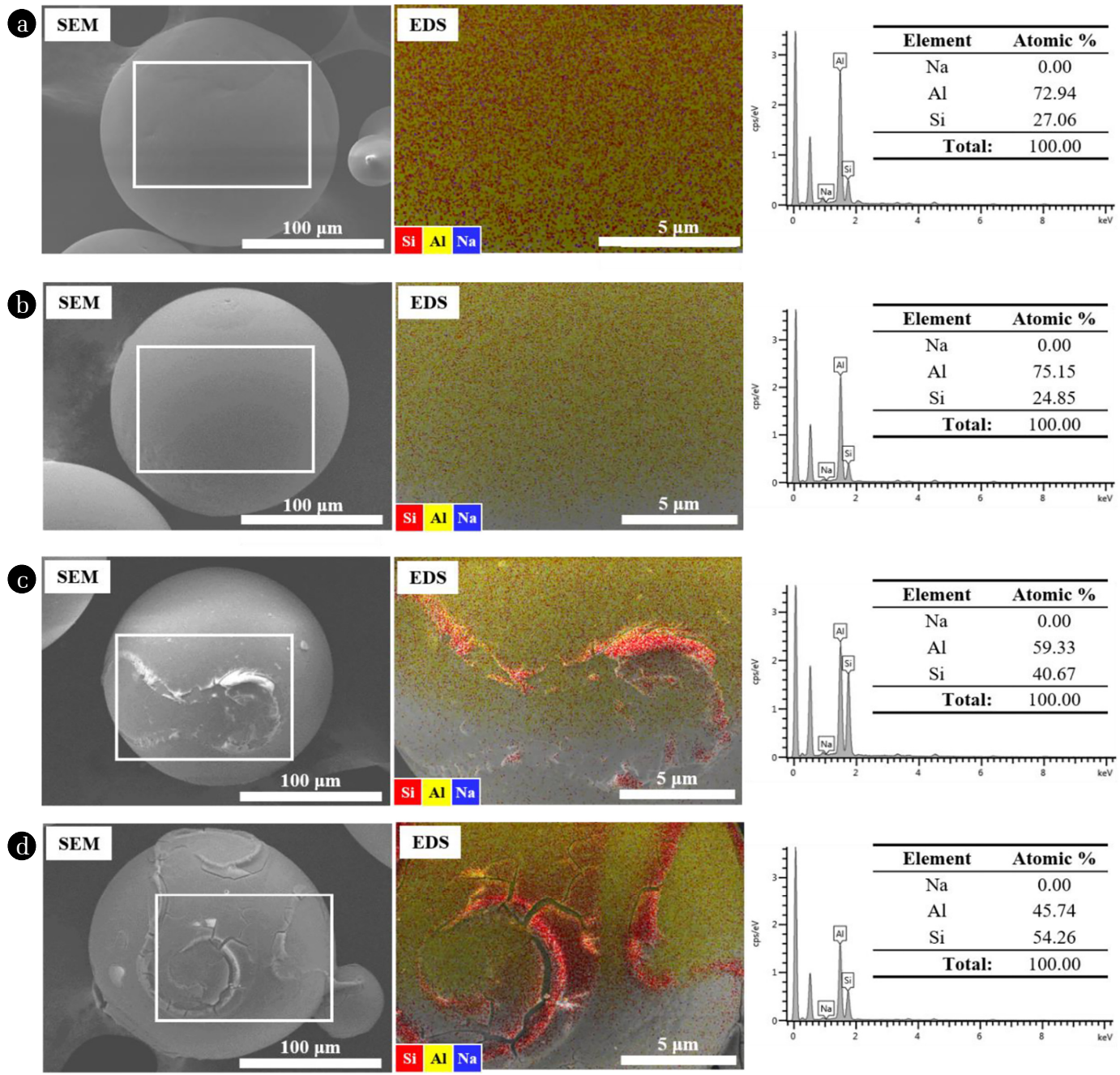

Fig. 3. SEM and EDS analysis results of samples: (a) artificial sand, (b) B1, (c) N1, and (d) A1.

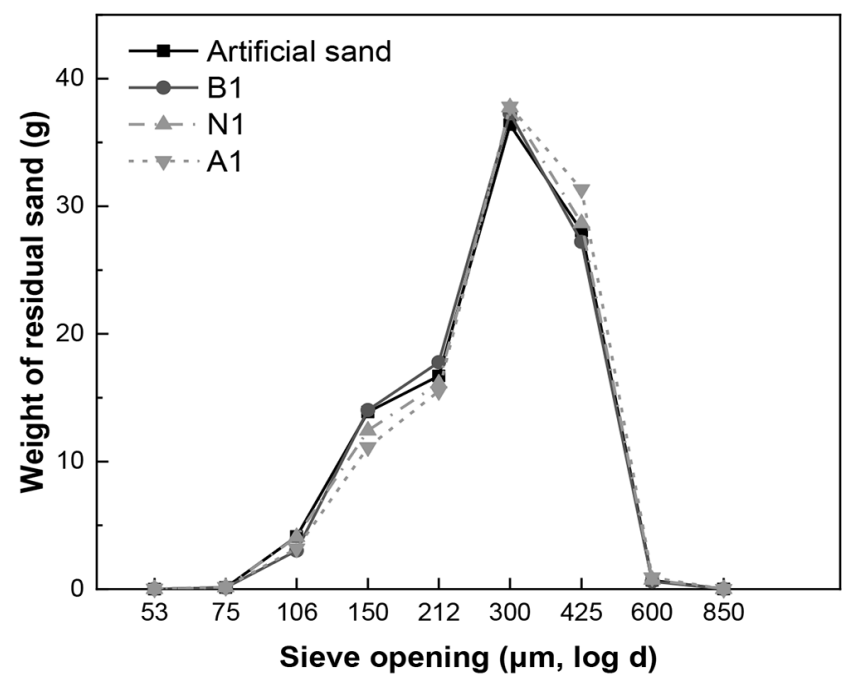

Fig. 4. Particle size distributions of artificial sand and regenerated sand (B1, N1, and A1).

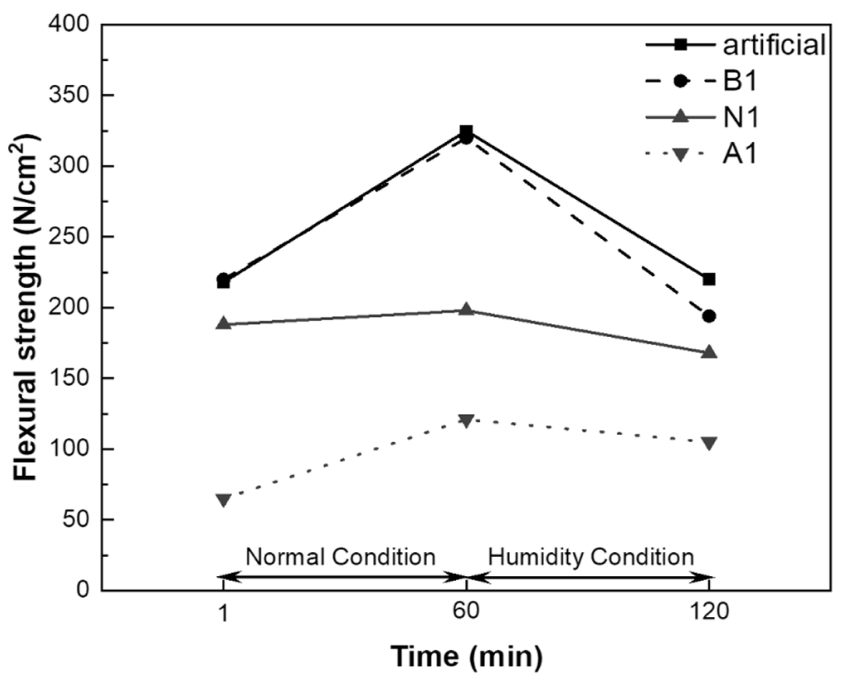

Fig. 5. Flexural strengths of artificial sand and regenerated sand. 


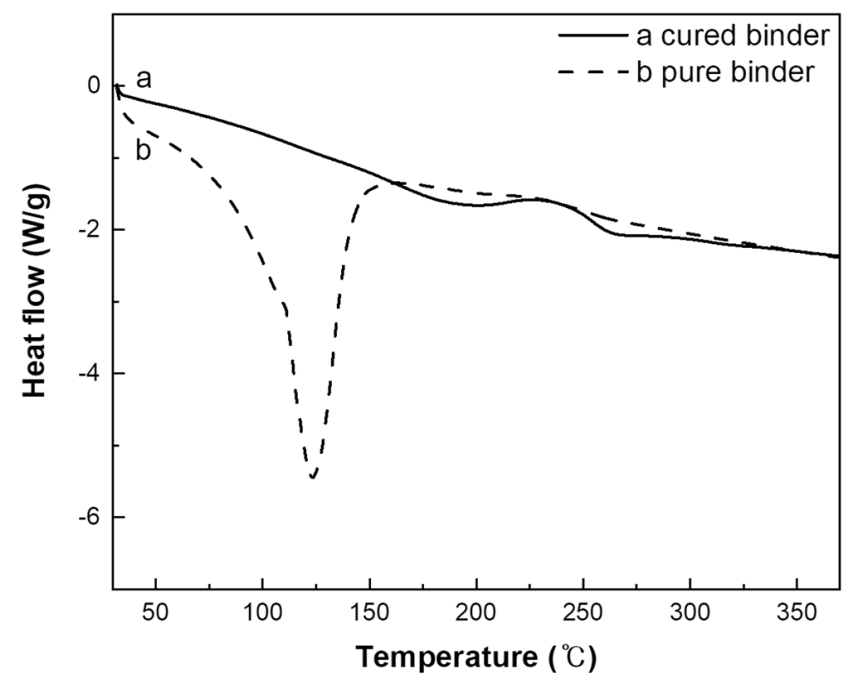

Fig. 6. DSC curves of cured binder at $150^{\circ} \mathrm{C}$ (curve a) and pure binder (curve b).

waste artificial sand changed, it was considered as an impurity. This was confirmed comparing the DSC curves of the new and cured binders (Fig. 6). The endothermic peak of the new binder (Fig. 6(b)) at $123^{\circ} \mathrm{C}$ confirmed the dehydration condensation reaction between the silanol groups of sodium silicate [31]. The binder cured at $150^{\circ} \mathrm{C}$ (Fig. 6(a)) exhibited no such a peak. This indicated that the dehydration condensation reaction did not occur, even when the cured binder was reheated, i.e., no bridges were formed between the sand particles, similar to the new binder. Therefore, because the residual binder on the regenerated sand became an impurity, the core strength of the regenerated sand with residual binder was comparatively lower [30].

\subsection{Re-treated $\mathrm{N} 1$ and $\mathrm{A} 1$}

Large amounts of remaining binder were present on the surface of the regenerated N1 and A1 sands. B1 (obtained using potassium hydroxide as the cleaning solution) effectively removed the entire binder. Therefore, N1 and A1 were regenerated once more using potassium hydroxide as the cleaning solution to determine its effect.

Table 1 compares the chemical compositions of the artificial sand, $\mathbf{N 2}$ and $\mathbf{A 2}$ samples. The $\mathrm{Na}_{2} \mathrm{O}$ content in artificial sand, N2 and A2 was $0.08 \%, 0.06 \%$, and $0.06 \%$, respectively. The $\mathrm{SiO}_{2}$ contents for $\mathbf{N 2}$ and $\mathbf{A 2}$ were similar to that of the artificial sand. The $\mathrm{Al}_{2} \mathrm{O}_{3}$ content in $\mathbf{N 2}$ and $\mathbf{A 2}$ was slightly higher than that of the artificial sand.

Fig. S1 shows the SEM images of re-treated N1 and A1 samples. N1 and A1 exhibited several impurities on the surface (Fig. 2). In contrast, the surfaces of $\mathbf{N 2}$ and $\mathbf{A 2}$ (samples re-treated with the basic solution) were smooth and had no impurities.

Fig. 7 shows the flexural strengths of the re-treated N1 and A1 samples, which were compared with those of the artificial sand and B1. The flexural strengths of $\mathbf{N 2}$ and A2 after 1 min were 248 and $272 \mathrm{~N} / \mathrm{cm}^{2}$, respectively, and the flexural strengths of N2 and A2 after 60 min were 337 and $374 \mathrm{~N} / \mathrm{cm}^{2}$, respectively. The flexural strengths of N1 and A1 with remaining binder on

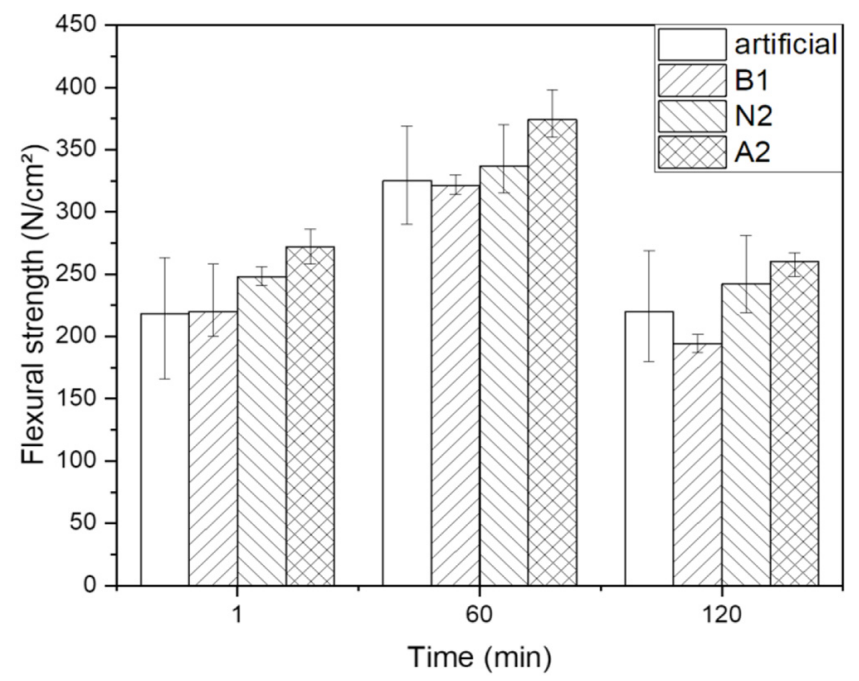

Fig. 7. Flexural strengths of re-treated sand (N2 and A2).

the surface were lower than that of the artificial sand, but the flexural strengths of $\mathbf{N 2}$ and $\mathbf{A} 2$ were higher than that of the artificial sand.

\section{Conclusions}

This study investigated the effect of binder removal and the reusability of regenerated sand according to the chemical solution used in the wet regeneration process. Comparing the characteristics of the artificial sand and the regenerated sand, using the basic solution was the most effective, among the three types of solutions, to remove the residual binder from waste artificial sand. The hydroxyl groups in the basic solution caused Si-O-Si cleavage that formerly bridged the sand particles; this was confirmed by XRF and zeta potential analysis. When the strengths of the artificial sand and the regenerated sand were compared, it was observed that the strength of regenerated sand treated with the basic solution (B1) was similar to that of the artificial sand. Moreover, the regenerated sand treated with neutral and acidic solutions (N1 and A1) had lower strength than the artificial sand. When N1 and A1 were re-treated with the basic solution to remove residual binder, the strengths of the regenerated sand (N2 and A2) increased. These results indicated that the residual binder on the surface of regenerated sand decreased the strength of regenerated sand, because it hindered the formation of binder bridges due to complete curing reaction of the silanol groups of the residual binder. This was demonstrated through the DSC curve of the binder.

Therefore, the potassium hydroxide solution was most suitable in the wet regeneration process of waste artificial sand using inorganic binders.

Several studies were conducted to compare the results of dry and wet regeneration of waste sand by using inorganic binders $[14,17]$. The characteristics of regenerated sand using wet regeneration compared to dry regeneration were similar to those of the raw sand and in this study, and the properties of regenerated sand using basic solution were similar to those of the raw sand. 
However, wet regeneration can lead to problems related to wastewater treatment, although studies have been reported regarding biological treatment [32]. Further research on the treatment of the wastewater generated from the experiments described in this study will be conducted.

\section{Acknowledgements}

This study was supported by the Technology Innovation Program (20000126 and 10067386) funded by the Ministry of Trade, Industry \& Energy (MOTIE, Korea) and the Korea Institute of Industrial Technology (KITECH) through the Research and Development (KITECH EO-20-0140) grant.

\section{Author Contributions}

E.Y.K. (M.D.) conducted all the experiments and wrote the manuscript with input from all authors. K.H.K. (M.D., researcher) planned the experiments and revised the manuscript. J.H.B. (Ph.D., Senior researcher) elaborated the discussion of the experiments' results. I.S.H. (Professor) revised the manuscript. M.S.L. (Ph.D., Principal researcher) wrote and revised the manuscript.

\section{References}

1. Siddiquea R, Kaur G, Rajor A. Waste foundry sand and its leachate characteristics. Resour. Conserv. Recycl. 2010;54: 1027-1036.

2. Bhardwaj B, Kumar P. Waste foundry sand in concrete: A review. Constr. Build. Mater. 2017;156:661-674.

3. Guney Y, Sari YD, Yalcin M, Tuncan A, Donmez S. Re-usage of waste foundry sand in high-strength concrete. Waste. Manag. 2010;30:1705-1713.

4. Lin DF, Luo HL, Lin JD, Zhuang ML. Characterizations of temperature effects on sintered ceramics manufactured with waste foundry sand and clay. J. Mater. Cycles. Waste. Manag. 2018;20:127-136.

5. Venkatesan M, Zaib Q, Shah IH, Park HS. Optimum utilization of waste foundry sand and fly ash for geopolymer concrete synthesis using D-optimal mixture design of experiments. Resour. Conserv. Recycl. 2019;148:114-123

6. Mavroulidou M, Lawrence D. Can waste foundry sand fully replace structural concrete sand? J. Mater. Cycles. Waste. Manag. 2019;21:594-605

7. Basar HM, Aksoy ND. Pre-treatment of Waste Foundry Sand Via Solidification/Stabilization. CLEAN - Soil, Air, Water. 2013;41:94-101.

8. Li Y lei, Wu G hua, Liu W cai, Chen W cai, Zhang L, Wang $Y$ xin. Effect of reclaimed sand additions on mechanical properties and fracture behavior of furan no-bake resin sand. China. Foundry. 2017;14:128-137.

9. Mizuki T, Kanno T. Establishment of Casting Manufacturing Technology by Introducing an Artificial Sand Mold with Furan Resin and Realizing a Clean Foundry. Int. J. Met. 2018;12:772-778.
10. Wen S, Shen Q, Wei Q, et al. Material optimization and post-processing of sand moulds manufactured by the selective laser sintering of binder-coated $\mathrm{Al}_{2} \mathrm{O}_{3}$ sands. J. Mater. Process. Technol. 2015;225:93-102.

11. Kosuge K, Sunaga M, Goda R, Onodera H, Okane T. Cure and collapse mechanism of inorganic mold using spherical artificial sand and water glass binder. Mater. Trans. 2018;59:1784-1790.

12. Ying-Min L, Tian-Shu W, Wei-Hua L. Research on regeneration methods of animal glue waste sand for foundry. R. Soc. Open. Sci. 2018;5:172-270.

13. Park CL, Kim BG, Yu Y. The regeneration of waste foundry sand and residue stabilization using coal refuse. J. Hazard. Mater. 2012;203-204:176-182

14. Wang L, Jiang W, Liu F, Fan Z. Investigation of parameters and mechanism of ultrasound-assisted wet reclamation of waste sodium silicate sands. Int. J. Cast. Met. Res. 2018;31:169-176.

15. Hefei City Tenver Precision Casting Co., Ltd., Regeneration treatment method of clay wet type used sand. 105903894 (2016.08.31), China Patent

16. Jang JE, Jung ES, Manufacturing method of recycling sand using waste foundry sand. 10-0760646, Korea Patent

17. Fan Z, Huang N, Wang H, Dong X. Dry reusing and wet reclaiming of used sodium silicate sand. China. Foundry. 2005;2:38-43.

18. Yang X, Roonasi P, Holmgren A. A study of sodium silicate in aqueous solution and sorbed by synthetic magnetite using in situ ATR-FTIR spectroscopy. J. Colloid. Interface. Sci. 2008;328:41-47.

19. Ko EY, Kim KH, Baek JH, Hwang IS, Lee MS. Characteristics of the chemical regeneration for used artificial sand according to the $\mathrm{pH}$ value of chemical solution (in Korean). Korea Foundry Society Spring meeting. 2019.

20. Bae MA, Kim MH, Park JW, Lee MS. Effect of additives on the sand burning of inorganic binder in Al-Si7Mg alloy casting. J. Korean. Inst. Met. Mater. 2018;56:327-333.

21. Lucas S, Tognonvi MT, Gelet JL, Soro J, Rossignol S. Interactions between silica sand and sodium silicate solution during consolidation process. J. Non. Cryst. Solids. 2011;357:1310-1318.

22. Fan ZT, Huang NY, Dong XP. In house reuse and reclamation of used foundry sands with sodium silicate binder. Int. J. Cast. Met. Res. 2004;17:51-56.

23. Lim HM, Lee J, Jeong J-H, Oh S-G, Lee S-H. Comparative Study of Various Preparation Methods of Colloidal Silica. Engineering 2010;02:998-1005.

24. Adelman JG, Elouatik S, Demopoulos GP. Investigation of sodium silicate-derived gels as encapsulants for hazardous materials - The case of scorodite. J. Hazard. Mater. 2015;292:108-117.

25. Kouassi SS, Tognonvi MT, Soro J, Rossignol S. Consolidation mechanism of materials obtained from sodium silicate solution and silica-based aggregates. J. Non. Cryst. Solids. 2011;357:30133021.

26. Yang X, Roonasi P, Holmgren A. A study of sodium silicate in aqueous solution and sorbed by synthetic magnetite using in situ ATR-FTIR spectroscopy. J. Colloid. Interface. Sci. 2008;328:41-47.

27. Hartmut P, Bernhard ES. Inorganic binders : for mould and core production in the foundry. Berlin : Fachverlag Schiele $\mathcal{E}$ Schö̈; 2014. 
28. Holtzer M, Górny M, Dańko R. Microstructure and Properties of Ductile Iron and Compacted Graphite Iron Castings. SpringerBriefs in Materials; 2015. p. 27-43.

29. Parappagoudar MB, Pratihar DK, Datta GL. Modeling and Analysis of Sodium Silicate-Bonded Moulding Sand System Using Design of Experiments and Response Surface Methodology. J. Manuf. Sci. Prod. 2012;11:1-14.

30. Khan MM, Singh M, Jadhav GN, Mahajani SM, Mandre S.
Characterization of Waste and Reclaimed Green Sand Used in Foundry Processing. Silicon. 2020;12:677-691.

31. Zhou X, Yang J, Su D, Qu G. The high-temperature resistant mechanism of $\alpha$-starch composite binder for foundry. J. Mater. Process. Technol. 2009;209:5394-5398.

32. Wang H, Fan Z, Yu S, Liu F, Li X. Wet reclamation of sodium silicate used sand and biological treatment of its wastewater by Nitzchia palea. China. Foundry. 2012;9:34-38. 